\title{
High-rate capability of supercapacitors based on
}

\section{tannin-derived ordered mesoporous carbons}

\author{
Jimena Castro-Gutiérrez, ${ }^{\dagger}$ Noel Diez,,${ }^{\ddagger}$ Marta Sevilla,${ }^{\ddagger}$ Maria Teresa Izquierdo, ${ }^{\S}$ Jaafar

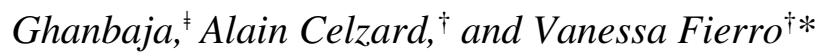

† Université de Lorraine, Institut Jean Lamour, UMR CNRS 7198. 27 Rue Philippe Séguin, 88051 Epinal Cedex 9, France.

¥ Instituto Nacional del Carbón (CSIC). P.O. Box 73, 33080 Oviedo, Spain

§ Instituto de Carboquímica (ICB-CSIC). Miguel Luesma Castán 4, E-50018 Zaragoza, Spain

${ }^{\ddagger}$ Université de Lorraine, Institut Jean Lamour UMR CNRS 7198. 2 Allée André Guinier, BP 50840, 54011 Nancy Cedex

Keywords: Ordered Mesoporous Carbon, Electrochemistry, Supercapacitors, Tannin

\begin{abstract}
Ordered mesoporous carbons (OMCs) are produced by an easy, fast and green surfactant-water-assisted mechanochemical mesostructuration (SWAMM) method, using only tannin, water and Pluronic ${ }^{\circledR}$ F127 as raw materials. OMCs are physically activated with $\mathrm{CO}_{2}$ to increase their surface area from $\sim 500 \mathrm{~m}^{2} \mathrm{~g}^{-1}$ to $\sim 2000 \mathrm{~m}^{2} \mathrm{~g}^{-1}$ while maintaining the mesoporosity fairly unaltered, which allow studying the effect of the micropore size distribution on the supercapacitors performances both in aqueous and organic electrolytes. Selected activated OMCs (AOMCs) reach maximum cell capacitance values of 37 and $27 \mathrm{~F} \mathrm{~g}^{-1}$, at $0.2 \mathrm{~A} \mathrm{~g}^{-1}$, in aqueous and organic electrolytes, respectively. High long-term stabilities over time and after continuous
\end{abstract}


cycling are found for the tested AOMCs in both kinds of electrolyte. High rate capabilities are achieved at high current densities with capacitance retentions up to $70 \%$ at $80 \mathrm{~A} \mathrm{~g}^{-1}$ and $44 \%$ at $40 \mathrm{~A} \mathrm{~g}^{-1}$ in aqueous and organic electrolytes, respectively, due to a suitable pore size distribution that promotes ion diffusion into the electrodes, in particular for the material activated during 75 $\min$.

\section{Introduction}

Due to both oil reserves depletion and increasing global warming, a transition towards environment-friendly technologies for producing and storing energy is required. Supercapacitors (SCs) are devices that store energy thanks to the creation of an electrostatic double layer (EDL) made from the interaction of electrolyte ions and the surface of electrodes. Thus, SCs are able to deliver energy at high rates, making them suitable for applications in electric vehicles, as energy backups or in hybrid systems along with batteries. ${ }^{1-3}$ However, the EDL mechanism for energy storage in SCs is associated with low values of specific energy, which is the main drawback in comparison with batteries. Attempts to increase the specific energy of SCs are centred on the development of high surface area porous materials and on the control of pore size, although surface chemistry modification, i.e., introduction of heteroatoms into the carbon structure, is also a frequent path to enhance the performances through pseudocapacitance contributions in SCs and in hybrid capacitors. ${ }^{4,5}$ Mesoporosity in carbon materials improves ion diffusion towards micropores, hence ordered mesoporous carbons (OMCs) were considered for use in electrochemical applications. ${ }^{1,6,7}$ However, as-synthesised OMCs usually have low to moderate surface areas, and an additional activation process is generally needed to enhance their textural characteristics and thus their electrochemical performances. Therefore, activated OMCs 
(AOMCs) are valuable materials in energy storage devices due to their high surface area and hierarchical pore structure that facilitates the diffusion of electroactive species. ${ }^{1,2,8}$

The usual synthesis methods of OMCs involve the polymerisation of the carbon precursor in the presence of a hard or soft template followed by pyrolysis. Whereas the heating process eliminates soft templates, hard templates need to be removed afterwards. OMCs are usually based on precursors of petrochemical origin, their synthesis may take several days, and hazardous substances are often used as crosslinkers or to remove the hard templates. ${ }^{9}$ Many efforts to synthesise OMCs from biosourced materials by hard- and soft-templating methods have been made. ${ }^{10-17}$ In particular, condensed tannins extracted from trees (mimosa, quebracho and pine, among others), which are principally based on flavonoid-type polyphenols, are able to undergo autocondensation reactions and hence do not require using crosslinkers. ${ }^{18}$ This remarkable feature makes them suitable, non-toxic and environment-friendly alternative carbon precursors to resorcinol or phenol. Specifically, mimosa tannin has been successfully used as carbon precursor for the production of OMCs by evaporation-induced self-assembly, ${ }^{13}$ by phase separation ${ }^{14,15}$ and, more recently, by mechanosynthesis. ${ }^{16,17}$ The simplicity and the shorter time required for OMCs synthesis by the latter method should increase its importance in the near future.

Herein, a one-pot surfactant-water-assisted mechanochemical mesostructuration (SWAMM) method is used to produce OMCs. This technique only requires using mimosa tannin as carbon precursor, Pluronic ${ }^{\circledR}$ F127 as pore structuring agent, and small amounts of water. ${ }^{17}$ The effects of $\mathrm{CO}_{2}$ activation of the tannin-derived OMCs on their porosity, surface chemistry and electrochemical performances are studied. The successive preparation steps to obtain the 
AOMCs are schematised in Figure 1: synthesis of the mesophase by ball milling, pyrolysis to produce the OMCs, and final $\mathrm{CO}_{2}$ activation in order to increase their specific surface area. After activation, surface areas close to $2000 \mathrm{~m}^{2} \mathrm{~g}^{-1}$ are obtained while the mesoporous structure is fully maintained. Selected AOMCs were tested as electrodes for SCs in aqueous and organic electrolytes by cyclic voltammetry and galvanostatic charge-discharge methods. From the selected AOMCs, maximum cell capacitance values of 37 and $27 \mathrm{~F} \mathrm{~g}^{-1}$ (at $0.2 \mathrm{~A} \mathrm{~g}^{-1}$ ) are reached in aqueous and organic electrolytes, respectively. A high rate capability is attained, with capacitance retentions of $70 \%$ at $80 \mathrm{~A} \mathrm{~g} \mathrm{~g}^{-1}$ and $44 \%$ at $40 \mathrm{~A} \mathrm{~g}^{-1}$ in aqueous and organic electrolytes, respectively. Additionally, long-term stabilities over time and after 10000 continuous cycles, above 94 and $86 \%$ in aqueous and organic electrolytes, respectively, are found.

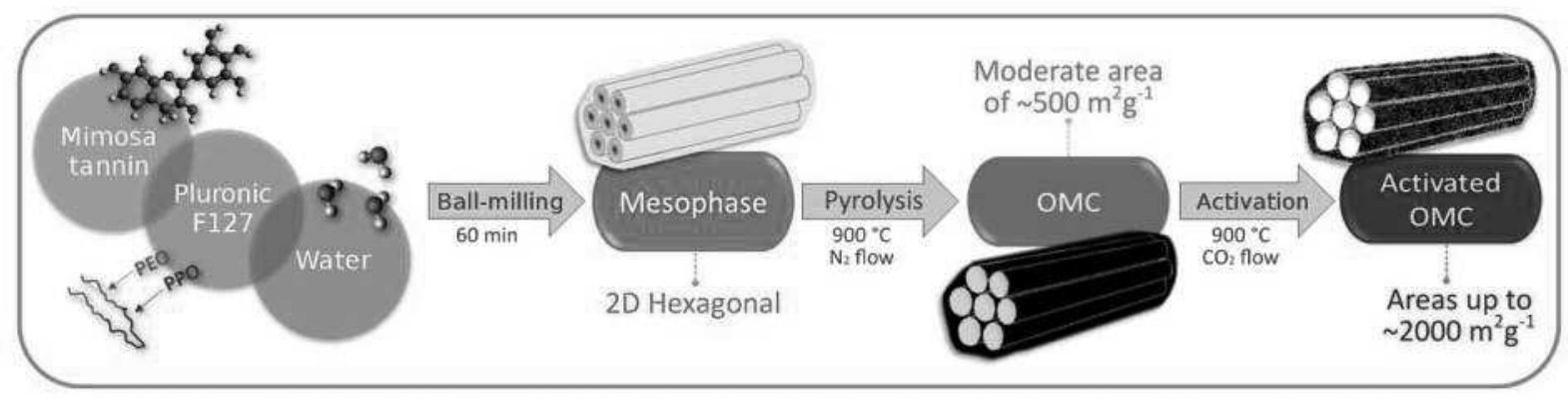

Figure 1. Scheme of the synthesis method of activated ordered mesoporous carbons derived from mimosa tannin through the SWAMM process (see text).

\section{Experimental methods}

Materials. Mimosa tannin extract, commercially available under the name Fintan OP and kindly provided by the company SilvaChimica (St Michele Modovi, Italy), was used as carbon precursor. It is a light-brown powder containing $80-82 \%$ of phenolic material based on flavonoid units. Pluronic $®$ F127 from Sigma-Aldrich was used as pore structuring agent. 
Synthesis of OMCs. The mechanosynthesis method is detailed elsewhere. ${ }^{17}$ Briefly, mimosa tannin extract (2 g), F127 (0.75 g) and water (1.75 g) were grounded together in a planetary mill (PM 100, Retsch, with agate bowl and balls) during 60 min at a constant rotating speed of 500 rpm. The paste-like materials thus recovered were placed in a quartz boat and directly submitted to carbonisation at $900{ }^{\circ} \mathrm{C}$ at a rate of $1{ }^{\circ} \mathrm{C} \mathrm{min}^{-1}$ in a quartz tube (inner diameter of $3.4 \mathrm{~cm}$ ) under $\mathrm{N}_{2}$ flow $\left(100 \mathrm{~mL} \mathrm{~min}{ }^{-1}\right)$. The final temperature was held for $1 \mathrm{~h}$ and then the materials were left to cool down naturally under $\mathrm{N}_{2}$ flow. The as-synthesised material was labelled CTPW, standing for Carbonised Tannin-Pluronic-Water.

Activation. Before $\mathrm{CO}_{2}$ activation, the carbonised materials were manually grounded to get a homogenous particle size. The temperature was raised up to $900{ }^{\circ} \mathrm{C}$ at a rate of $5{ }^{\circ} \mathrm{C} \mathrm{min}-1$ under $\mathrm{N}_{2}$ flow $\left(100 \mathrm{~mL} \mathrm{~min}{ }^{-1}\right)$ in the same device as that used for carbonisation. Afterwards, $\mathrm{N}_{2}$ was switched to $\mathrm{CO}_{2}\left(50 \mathrm{~mL} \mathrm{~min}^{-1}\right)$ and held for a time ranging from 15 to $120 \mathrm{~min}$. Then, $\mathrm{CO}_{2}$ was switched back to $\mathrm{N}_{2}$ and the samples were left to cool down until room temperature. Samples were labelled At-CTPW, where " $t$ " stands for the activation time in minutes.

Textural analysis. $\mathrm{N}_{2}\left(\right.$ at $\left.-196{ }^{\circ} \mathrm{C}\right)$ and $\mathrm{CO}_{2}\left(\right.$ at $\left.0{ }^{\circ} \mathrm{C}\right)$ adsorption experiments were carried out with ASAP 2020 and ASAP 2420 (Micromeritics) automatic adsorption devices, respectively. Samples were degassed under secondary vacuum before adsorption analysis during at least $48 \mathrm{~h}$ at $110{ }^{\circ} \mathrm{C}$. Microactive ${ }^{\circledR}$ software provided by Micromeritics was used to apply the BET method to $\mathrm{N}_{2}$ isotherms and to obtain: (i) the BET area, $A_{B E T}$, and (ii) the pore size distribution (PSD) using the Barret-Joyner-Halenda (BJH) method with the Kruk-Jaroniec-Sayari (KJS) correction (BKH-KJS) applied to the desorption branch of the $\mathrm{N}_{2}$ isotherms. SAIEUS® software, also from Micromeritics, was used to apply the 2D non-local density functional theory for heterogeneous surface (2D-NLDFT HS) to $\mathrm{N}_{2}$ and $\mathrm{CO}_{2}$ isotherms. Such model was used to calculate the PSD 
and the following parameters: surface area, $S_{N L D F T}$; ultramicropore volume (pore size $w<0.7$ $\mathrm{nm}), V_{u \mu}$; supermicropore volume $(0.7<w<2 \mathrm{~nm}), V_{s \mu}$; total pore volume, $V_{\text {tot }}$; mesopore volume, $V_{\text {meso }}=V_{\text {tot }}-V_{s \mu}-V_{u \mu}$; and average pore size, $w_{a v}$, according to:

$$
w_{a v}=\frac{\sum_{i}\left(\frac{d V}{d w}\right)_{i} w_{i}}{\sum_{i}\left(\frac{d V}{d w}\right)_{i}}
$$

Morphological analysis. Transmission electron microscopy (TEM) images were obtained with a JEM-ARM 200F Cold FEG TEM/STEM operating at $200 \mathrm{kV}$, using a spherical aberration (Cs) probe and image correctors. Samples were prepared for observation by dispersing carbon powder in ethanol using a low-power sonication bath, after which a single drop of suspension was deposited onto a carbon-coated copper TEM grid (200 mesh). Small-angle X-ray scattering (SAXS) measurements were carried out in a Bruker D8 Advance X-ray powder diffractometer equipped with an $\mathrm{X}$-ray source with a $\mathrm{Cu}$ anode working at $40 \mathrm{kV}$ and $40 \mathrm{~mA}$, a graphite monocromator and a scintillation detector. Silver behenate was used as low-angle diffraction standard calibration for height correction, and data given for $\mathrm{d}(100)$ planes are collected.

Chemical analysis. Elemental Analysis (EA) was performed in an Elementar Vario EL Cube analyser wherein the oxygen content was measured. X-Ray Photoelectron Spectroscopy (XPS) was performed on an ESCAPlus OMICROM system equipped with a hemispherical electron energy analyser and an area of analysis of $1.75 \times 2.75 \mathrm{~mm}$. The device was equipped with an $\mathrm{Mg}$ $\mathrm{X}$-Ray source $(1253.6 \mathrm{eV})$ and was operated at $15 \mathrm{kV}$ and $15 \mathrm{~mA}$. Pass energies of $50 \mathrm{eV}$ and 20 $\mathrm{eV}$ were used for survey and high-resolution scans, respectively. The $\mathrm{C} 1 \mathrm{~s}$ and $\mathrm{O} 1 \mathrm{~s}$ peaks were treated with the CASA software, and the atomic content of each element was calculated from the atomic sensitivity factors. 
Electrochemical characterisation. A paste was prepared by mixing the AOMC under study with carbon black and PTFE in an 85:5:10 weight ratio. Then, disc-shaped electrodes with carbon loads of $9.9 \pm 1.1 \mathrm{mg} \mathrm{cm}^{-2}$ were cut from the paste. Supplementary tests were carried out with lower carbon loads (CL) of $5.7 \pm 0.5 \mathrm{mg} \mathrm{cm}^{-2}$ for direct comparison with data reported in the literature. Electrodes were impregnated with $1 \mathrm{M} \mathrm{H}_{2} \mathrm{SO}_{4}$ or $1 \mathrm{M} \mathrm{TEABF}_{4} / \mathrm{ACN}$ used as aqueous and organic electrolytes, respectively. Measurements were carried out using a VMP3 (Bio-Logic) electrochemical workstation for which a two-electrode cell was used to test the electrochemical performances: two electrodes of comparable mass, separated by a porous glass fibre mat, were placed between either two gold (in $\mathrm{H}_{2} \mathrm{SO}_{4}$ ) or two stainless steel (in $\left.\mathrm{TEABF}_{4} / \mathrm{ACN}\right)$ current collectors. Cyclic voltammetry (CV) was carried out within a potential window of $1 \mathrm{~V}$ for the aqueous electrolyte and of $2.7 \mathrm{~V}$ for the organic one. The cell specific capacitance $\left(C_{\text {cell }}, \mathrm{F} \mathrm{g}^{-1}\right)$ was calculated according to:

$$
C_{c e l l}=\frac{\oint I d V}{s \Delta V m}
$$

where $I$ is the measured current (A), $s$ is the scan rate $\left(\mathrm{V} \mathrm{s}^{-1}\right), \Delta V$ is the potential window $(\mathrm{V})$, and $m$ is the mass of active material in the two electrodes $(\mathrm{g})$. Galvanostatic charge-discharge (GCD) tests were conducted in the corresponding potential windows for each electrolyte. The change of $C_{c e l l}$ with the applied current was calculated using the following formula:

$$
C_{\text {cell }}=\frac{I}{4(d V / d t) m_{e}}
$$

were $I$ is the applied current density (calculated based on the mass of one electrode), $d V / d t$ is the slope of the discharge curve after removing the potential drop $(i R)$, determined using the upper half of the curve considering that SCs are usually operated in the range of $V_{\max }$ to $1 / 2 V_{\max }$ 
${ }^{19,20}$ and $m_{e}$ is the mass of active material in one electrode. Taking into account the former consideration, the specific energy $\left(E, \mathrm{Wh} \mathrm{kg}^{-1}\right)$ and the specific power $\left(P, \mathrm{~W} \mathrm{~kg}^{-1}\right)$ should be calculated between the two operating potentials, $V_{1=} V_{\max }-i R$ and $V_{2}=1 / 2 V_{\max }$, according to:

$$
\begin{gathered}
E=\frac{1}{2} C_{\text {cell }}\left(V_{1}^{2}-V_{2}^{2}\right) \\
P=\frac{E}{\Delta t_{12}}
\end{gathered}
$$

where $\Delta t_{12}$ is the time (s) required for discharging the capacitor between the two operating potentials. However, as most published studies used the full discharge curve for energy and power calculations, $V_{2}$ was considered to be equal to zero and $\Delta t_{12}$ to be the time for full discharge.

Long-term stability was evaluated by continuous cycling at $5 \mathrm{~A} \mathrm{~g}^{-1}$ over 10000 or 8000 cycles for aqueous or organic electrolytes, respectively. Besides, it has been reported that potentiostatic hold tests also provide valuable information about the long-term stability, as they evaluate the performance under more demanding conditions than continuous cycling; ${ }^{21}$ thus, materials' stability was alto tested by holding the corresponding cell voltage at its maximum during $50-72$ h. In order to characterize the impedance of the as-assembled supercapacitors, electrochemical impedance spectroscopy (EIS) measurements were performed at open circuit voltage using a 10 $\mathrm{mV}$ AC amplitude signal whose frequency ranged from $1 \mathrm{mHz}$ to $100 \mathrm{kHz}$.

Finally, additional tests were performed using $1 \mathrm{M} \mathrm{Na}_{2} \mathrm{SO}_{4}$ as neutral aqueous electrolyte in order to compare the performance to that obtained in acidic medium. 


\section{Results and Discussion}

\subsection{Textural properties}

Figure 2a shows the $\mathrm{N}_{2}$ adsorption-desorption isotherms of the as-synthesised OMC, label CTPW, and the AOMCs label At-CTPW, " $t$ " ranging from 15 to 120 min of activation. The corresponding textural properties are listed in Table S1 of the Supporting information. All the materials exhibit isotherms corresponding to micro-mesoporous materials, for which the adsorbed volume keep increasing in the range of relative pressures $p / p_{0}$ from 0.1 to 0.4 , and the slope increases with the activation time, indicating a progressive pore widening. The "knee" of the isotherm at low $p / p_{0}$ indeed becomes gradually broader and more open when the activation time increases due to pore filling in wide micropores. ${ }^{22}$ Such pore filling induces an overestimation of the surface area by the BET method, which assumes a monolayer adsorption of the probe molecule. ${ }^{23-25}$ On the contrary, the BET method underestimates the surface area when very narrow pores exist, because only one single pore wall is taken into account. ${ }^{26}$ The $2 \mathrm{D}$ NLDFT HS method ${ }^{27}$ applied to both $\mathrm{N}_{2}$ and $\mathrm{CO}_{2}$ adsorption isotherms provides a much better estimation of the surface area and hence of its contribution to the electrochemical performances of SCs. ${ }^{24,28,29}$ Therefore, in the present study, the analysis using the textural properties calculated from the 2D-NLDFT HS method is prioritised. In Figure 2b, the BET and the NLDFT surface areas, $A_{B E T}$ and $S_{N L D F T}$, respectively, are plotted as a function of burn-off (BO). It can be noticed that $A_{B E T}$ and $S_{N L D F T}$ values cross at $\mathrm{BO}$ around 0.4 . For $\mathrm{BO}<0.4$, the pristine OMC and poorly activated samples still present narrow pores so that the area is underestimated by the BET method: $A_{B E T}<S_{N L D F T}$. In contrast, for more activated samples such as A75-CTPW and A90CTPW, $A_{B E T}$ is higher than $S_{N L D F T}$ due to multilayer adsorption in the wider pores. Both $A_{B E T}$ and $S_{N L D F T}$ increase with the BO, reaching a maximum at $\mathrm{BO} \sim 0.8$ and then decrease drastically 
due to pore broadening and merging. Figure S1 confirms that the pores widen with activation time: the average pore size $\left(w_{a v}\right)$ increases as a function of $\mathrm{BO}$, from 0.94 to $1.57 \mathrm{~nm}$ for CTPW and A120-CTPW, respectively.

Figure $2 \mathrm{c}$ presents the changes of pore volume with $\mathrm{BO}$, in the different ranges of pore width $(w)$ : ultramicropore $(w<0.7 \mathrm{~nm})$, supermicropore $(0.7<w<2 \mathrm{~nm})$ and mesopore $(2<w<50$ $\mathrm{nm})$ volumes, $V_{u \mu}, V_{s \mu}$ and $V_{\text {meso }}$, respectively. All materials exhibit a decrease of $V_{u \mu}$ and an increase of $V_{s \mu}$ and $V_{\text {meso }}$, up to a $\mathrm{BO}$ of $\sim 0.8$, due to pore widening by $\mathrm{CO}_{2}$ activation. Further activation results in a drastic decrease of pore volume caused by pore merging, producing the vanishing of the porosity of the AOMC at $120 \min (\mathrm{BO}=0.94)$.

Figure $2 \mathrm{~d}$ and Figure $2 \mathrm{f}$ display the pore size distribution (PSD) in the mesopore range calculated by the BJH model with the KJS correction (BJH-KJS), as well as the PSD calculated by the 2D-NLDFT HS method in the whole pore diameter interval, respectively. In the mesopore range, a progressive development of pores narrower than $4 \mathrm{~nm}$ and the widening of the peak centred at $4.6 \mathrm{~nm}$ are observed with activation time until the nearly complete loss of the original mesoporous structure for A120-CTPW. Non- or poorly activated OMCs present two clear and separated pore systems corresponding to micro- and mesoporosity, whereas a continuous PSD is observed for BO $>0.59(t>75 \mathrm{~min})$, as shown in Figure 2f. Such non-discrete PSD might favour ion diffusion and hence improve the electrochemical performances of SCs. ${ }^{6}$ In addition, Figure 2e displays TEM images of the $2 \mathrm{D}$ hexagonal ordered mesoporous structure that withstands the activation process up to a $\mathrm{BO}$ of $78 \%$; this was confirmed by the SAXS measurements shown in Figure S2, where the peak associated to the ordered structure in the 100 direction is still present for the AOMCs. The decreased intensity and broadening of the SAXS peak is to be expected as the gasification of the carbon produce imperfections on the original 2D hexagonal structure. 

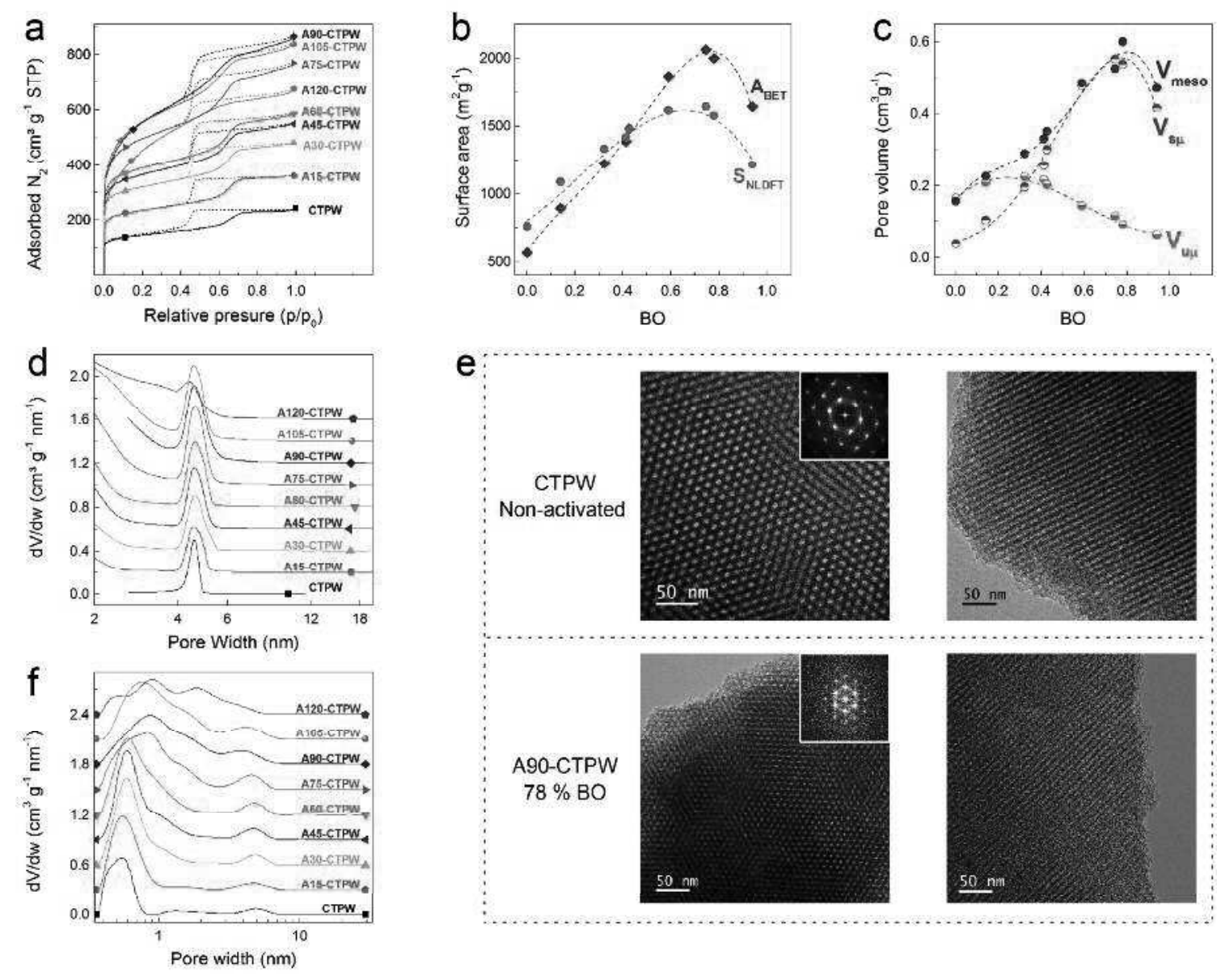

Figure 2. (a) $\mathrm{N}_{2}$ adsorption-desorption isotherms for the activated carbons and the as-synthesised material. (b) BET area and NLDFT surface area of the AOMCs as a function of burn-off, BO. (c) Changes of pore volume with BO. (d) Pore size distributions, PSDs, in the mesopore range obtained by using the BJH-KJS model applied to the desorption branch of the $\mathrm{N}_{2}$ isotherms. (e) TEM images, the inset shows the corresponding diffraction patterns, confirming the $2 \mathrm{D}$ hexagonal ordered mesopore structure of CTPW (non-activated) and A90-CTPW (78 \% BO). (f) PSDs obtained by using the 2D-NLDFT HS model applied to both $\mathrm{N}_{2}$ and $\mathrm{CO}_{2}$ adsorption isotherms. 


\subsection{Surface and bulk composition}

Figure S3a shows the oxygen content of the materials, measured in the bulk by elemental analysis (EA) and at the surface by XPS. CTPW present oxygen functionalities on the surface that are eliminated at low activation times $(t=15 \mathrm{~min})$, as suggested by the drastic drop of $\mathrm{O}$ content measured by XPS. Then, the $\mathrm{O}$ content increases with the activation time $(t>15 \mathrm{~min})$, and its concentration is always higher at the surface than in the bulk of the materials. It has been reported that a high oxygen content can improve the electrochemical performances of materials used as electrodes of SCs. ${ }^{30}$ However, not all the functional groups are useful and some of them may even have a negative impact on their performances. ${ }^{31}$ Quinone and carbonyl type functionalities (OI) are electrochemically active and can lead to redox reactions yielding pseudocapacitance contributions that allow increasing the amount of energy stored in the device. On the contrary, high-polarity $\mathrm{O}$ functionalities present in carboxylic groups (OIII) produce resistance to ion diffusion in aqueous electrolytes, reducing the performances at high current densities. $^{4}$

Figure $\mathrm{S} 3 \mathrm{~b}$ shows the relative contribution of each kind of $\mathrm{O}$ moiety to the $\mathrm{O} 1 \mathrm{~s}$ peak determined by XPS for the AOMCs; the complete assignment of the XPS peaks and the relative contributions of functionalities to the surface composition are listed in Table S2 of the Supporting information. The most common oxygen surface functionalities are hydroxyl groups in phenols (OII), in good agreement with the phenolic nature of the tannin used as carbon precursor. The second most important contribution comes from the OI group, and finally the OIII contributions are the least common. After activation, the relative amount of OII functionalities first decreases and then remains nearly constant with activation time, whereas OIII slightly increases and OI slightly decreases. Although the amount of oxygen surface functionalities 
globally increases with activation time, the majority of OII functionalities that are not electrochemically active in acid electrolyte along with the combined increase of OIII and decrease of OI could make negligible the pseudocapacitance contribution of the oxygen functionalities. On the other hand, the presence of heteroatoms in a carbon material is usually associated with a reduced lifetime; ${ }^{2}$ however, as it will be shown below, the activated materials tested as electrodes for SCs exhibited high long-term stability despite the presence of the aforementioned oxygen functionalities.

\subsection{Electrochemical characterisation}

The electrochemical performances of A30- to A90-CTPW materials as electrodes for SCs were first studied by cyclic voltammetry $(\mathrm{CV})$ in aqueous electrolyte $\left(1 \mathrm{M} \mathrm{H}_{2} \mathrm{SO}_{4}\right)$. Figure 3a displays the quasi-rectangular $\mathrm{CV}$ curves at $5 \mathrm{mV} \mathrm{s}^{-1}$ found for all the tested materials, representing a nearly ideal capacitive behaviour. The values of cell specific capacitance $\left(C_{c e l l}\right)$, calculated from the CV curves, are shown in Figure 3b, this plot shows that A75- CTPW reaches a maximum $C_{\text {cell }}$ of $40 \mathrm{~F} \mathrm{~g} \mathrm{~g}^{-1}$ at $5 \mathrm{mV} \mathrm{s}^{-1}$. In order to relate the capacitance to the pore texture, the normalised electrode capacitance $\left(C_{e N, B E T}\right)$ is plotted against $w_{a v}$ in Figure $3 \mathrm{c}$. For comparative purposes, the capacitance is normalised using $A_{B E T}$ instead of $S_{N L D F T}$, an increase of $C_{e N, B E T}$ is observed with the decrease of $w_{a v}$, which is in agreement with previously reported results, ${ }^{32,33}$ this capacitance increase is caused by a distortion of the solvated ions, that reduces de distance to the carbon surface. ${ }^{33}$ The values of the present study are slightly higher than those previously reported, which can be due to: (i) different measurement conditions for the electrochemical tests, e.g. scan rate; (ii) different ways of electrode preparation, e.g. carbon load or amount and type of binder; (iii) the calculation method of $w_{a v}$, either from the NLDFT model or from Dubinin's 
theory; or (iv) the limitations of the model that assumed unimodal PSDs. Most likely, the latter factor has the highest impact on the deviations from the model given the hierarchical micromesoporous nature of the AOMCs. Therefore, the bimodal nature of the PSDs might induce a shift towards higher $w_{a v}$ and hence produce a significant shift from the theoretical line (see again Figure 3c).

Further on, Figure 3d shows that only A60- and A75-CTPW samples retain more than $60 \%$ of their initial $C_{\text {cell }}$ when the scan rate increases from 5 to $500 \mathrm{mV} \mathrm{s}^{-1}$. Figure $3 \mathrm{e}$ shows the normalised electrode capacitance, with respect to $S_{N L D F T}\left(C_{e N, N L D F T}\right)$, at 5 and $500 \mathrm{mV} \mathrm{s}^{-1}$ as a function of $w_{a v}$; the continuous decrease of $C_{e N, N L D F T}$ with $w_{a v}$ that is observed at $5 \mathrm{mV} \mathrm{s}^{-1}$ does not hold anymore at high scan rates, for which a maximum is found for A75-CTPW. In addition, A60-CTPW presents a higher $C_{e N, N L D F T}$ than A45-CTPW at $500 \mathrm{mV} \mathrm{s}^{-1}$ despite their rather similar textural properties (see again Table S1 of the Supporting information). The main difference between these two samples is their pore size distribution (see again Figure 2f): both present a large peak centred on $0.6 \mathrm{~nm}$ but whose width is lower for A45-CTPW, $0.30 \mathrm{~nm}$, than for A60-CTPW, $0.86 \mathrm{~nm}$. On the other hand, A30- and A45-CTPW reach similar values of $C_{\text {cell }}$ $\sim 14 \mathrm{~F} \mathrm{~g} \mathrm{~g}^{-1}$ at $500 \mathrm{mV} \mathrm{s}^{-1}$, despite the higher $S_{N L D F T}$ of the latter, but their PSDs reveal isolated peaks for micro- and mesopore sizes in both samples. A90-CTPW is a particular case: the activation process has widen its pores with the concomitant decrease of $V_{\mu u}$ and increase of $V_{s \mu}$; wider pores do not allow solvated ion deformation, thus lessen the SC performance, as seen in Figure 3d and Figure 3e.

It is generally agreed that mesoporous structures facilitate ion diffusion into the micropores; ${ }^{2-}$ 4,14,33 herein, $\mathrm{CO}_{2}$ activation mainly develops pores with $w<4 \mathrm{~nm}$, which can ease ion mobility at high charging rate due to lower diffusion resistance. ${ }^{28}$ However, an optimum activation time 
needs to be found to avoid pore collapsing and the resultant loss of pore volume. Thus, the best outcomes displayed in Figure 3 for A60- and A75-CTPW, are the consequence of a combination of high $S_{N L D F T}$, that has a significant role at low scan rates, and an adequate PSD that favours ion diffusion at high scan rates.
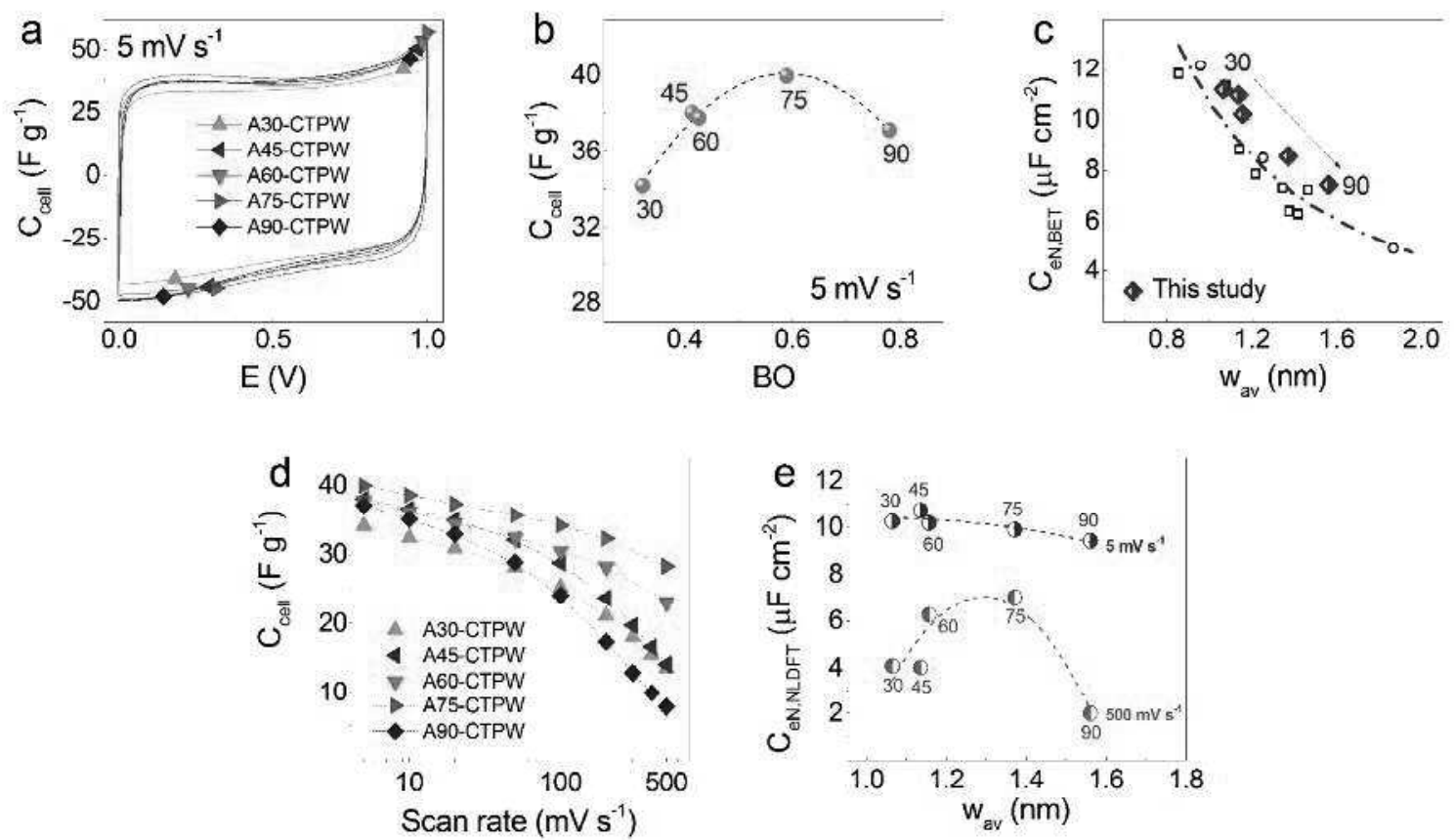

Figure 3. Electrochemical performances of A30- to A90-CTPW samples in aqueous electrolyte (1 $\mathrm{M} \mathrm{H}_{2} \mathrm{SO}_{4}$ ): (a) $\mathrm{CV}$ curves at $5 \mathrm{mV} \mathrm{s}^{-1}$; (b) cell specific capacitance, $C_{\text {cell }}$, as a function of burn-off (BO); (c) normalised electrode capacitance with respect to BET area, $C_{e N, B E T}$, as a function of average pore size, $w_{a v}$, compared to experimental (squares) and theoretical (dasheddotted line) data from previous studies; ${ }^{25,33,34}$ (d) $C_{\text {cell }}$ as a function of scan rate; (e) normalised capacitance with respect to NLDFT surface area, $C_{e N, N L D F T}$, as a function of $w_{a v}$. Labels in (b), (c) and (e) represent the activation time in minutes; lines in (b) and (e) are just guides for the eye. 
Because of their superior performance in CV experiments, A60- and A75-CTPW materials were more deeply characterised electrochemically. Figure 4a shows the quasi-rectangular curves obtained for the aforementioned samples at $5 \mathrm{mV} \mathrm{s}^{-1}$. Galvanostatic charge-discharge (GCD) tests result in triangular-shaped curves for A60- and A75-CPTW (Figure S4): good supercapacitor behaviour is revealed by the symmetry of the curves (coulombic efficiency $\sim 100$ $\%)$ and the small $i R$ drops at current densities up to $50 \mathrm{~A} \mathrm{~g}^{-1}$. A75-CTPW presents a slightly higher $C_{\text {cell }}$ of $37 \mathrm{~F} \mathrm{~g}^{-1}$ compared to A60-CTPW with $C_{\text {cell }}$ of $35 \mathrm{~F} \mathrm{~g}^{-1}$, both determined at $0.2 \mathrm{~A}$ $\mathrm{g}^{-1}$. Figure $4 \mathrm{~b}$ (top) shows that A75-CTPW exhibits a capacitance retention $\left(C_{\text {ret }}\right)$ of $70 \%$ at the highest value of applied current, $80 \mathrm{~A} \mathrm{~g}^{-1}$, while A60-CTPW reaches only a $C_{\text {ret }}$ of $51 \%$. The higher values of $C_{\text {ret }}$ of A75-CTPW are probably due to a lower equivalent series resistance, suggested by the lower potential drops than in A60-CTPW case. ${ }^{14,35}$ As a consequence, the values of specific energy and power are higher for A75-CTPW, as can be seen on the Ragonelike plot in Figure 4c, where the stored energy $(E)$ reaches a maximum of $5 \mathrm{Wh} \mathrm{kg}^{-1}$ with a power output $(P)$ of $44 \mathrm{~W} \mathrm{~kg}^{-1}$ at $0.2 \mathrm{~A} \mathrm{~g}^{-1}$. Besides, a long-term stability was evidenced by continuous GCD tests at $5 \mathrm{~A} \mathrm{~g}^{-1}$. Figure $4 \mathrm{~b}$ (bottom) shows that both selected samples present $C_{\text {ret }} \sim 98 \%$ after 10000 cycles and, by potentiostatic hold at $1 \mathrm{~V}$ it remains above $94 \%$ after 50 $\mathrm{h}$ as shown in Figure S5, thereby proving the robustness of the SCs based on tannin-derived ordered mesoporous carbons.

Most commercial SCs use organic electrolytes due to their wider potential window, hence the possibility of storing more energy than their aqueous counterparts. ${ }^{19}$ The electrochemical performance of the selected AOMCs was thus tested in an organic electrolyte $\left(1 \mathrm{M} \mathrm{TEABF}_{4}\right.$ in acetonitrile (ACN)); Figure 4d show the rectangular CV curves obtained for A60- and A75CTPW samples at $5 \mathrm{mVs}^{-1}$. A more important drop of $C_{r e t}$, than that of the GCD tests in aqueous 
electrolyte, is observed in Figure 4e (top), the decrease is $\sim 40 \%$ when the current increases up to $40 \mathrm{~A} \mathrm{~g} \mathrm{~g}^{-1}$. This is due to the combination of the bigger size of the organic electrolyte ions and its lower ionic conductivity, which increases both the equivalent distributed resistance and the equivalent series resistance, as can be seen in the Nyquist plots in Figure S6, and ultimately the total cell resistance. A slightly better performance is observed for A75-CTPW at low current densities, however as the current increased both tested materials presented the same performance. The PSD that favours ion diffusion in A75-CTPW at high current densities in aqueous electrolyte could no longer be enough to compensate for the low mobility of ions in the organic electrolyte. In addition, even if the ions reach the microporosity their bigger size difficult the access to it, thus reducing the available sites for the storage of charge and explaining also the lower values of specific capacitance when compared to the aqueous counterparts. Nonetheless, the materials maintain a high long-term stability with $C_{r e t}$ above $90 \%$ after 8000 cycles at $5 \mathrm{~A}$ $\mathrm{g}^{-1}$ (Figure $4 \mathrm{e}$ (bottom)) and of $86 \%$ by potentiostatic hold at $2.7 \mathrm{~V}$ after $72 \mathrm{~h}$ (Figure S5). As expected, the values of specific energy and power are higher than those attained in aqueous electrolyte. A maximum $E$ of $c a .28 \mathrm{Wh} \mathrm{kg}^{-1}$ with a $P$ output of $138 \mathrm{~W} \mathrm{~kg}^{-1}$ is reached by A75CTPW, and similar values are reached by A60-CTPW, as revealed by the Ragone-like plot in Figure 4f. Importantly, at a high power of $12 \mathrm{~kW} \mathrm{~kg}^{-1}$, both SCs are still able to provide $\sim 13 \mathrm{~W}$ $\mathrm{kg}^{-1}$. 

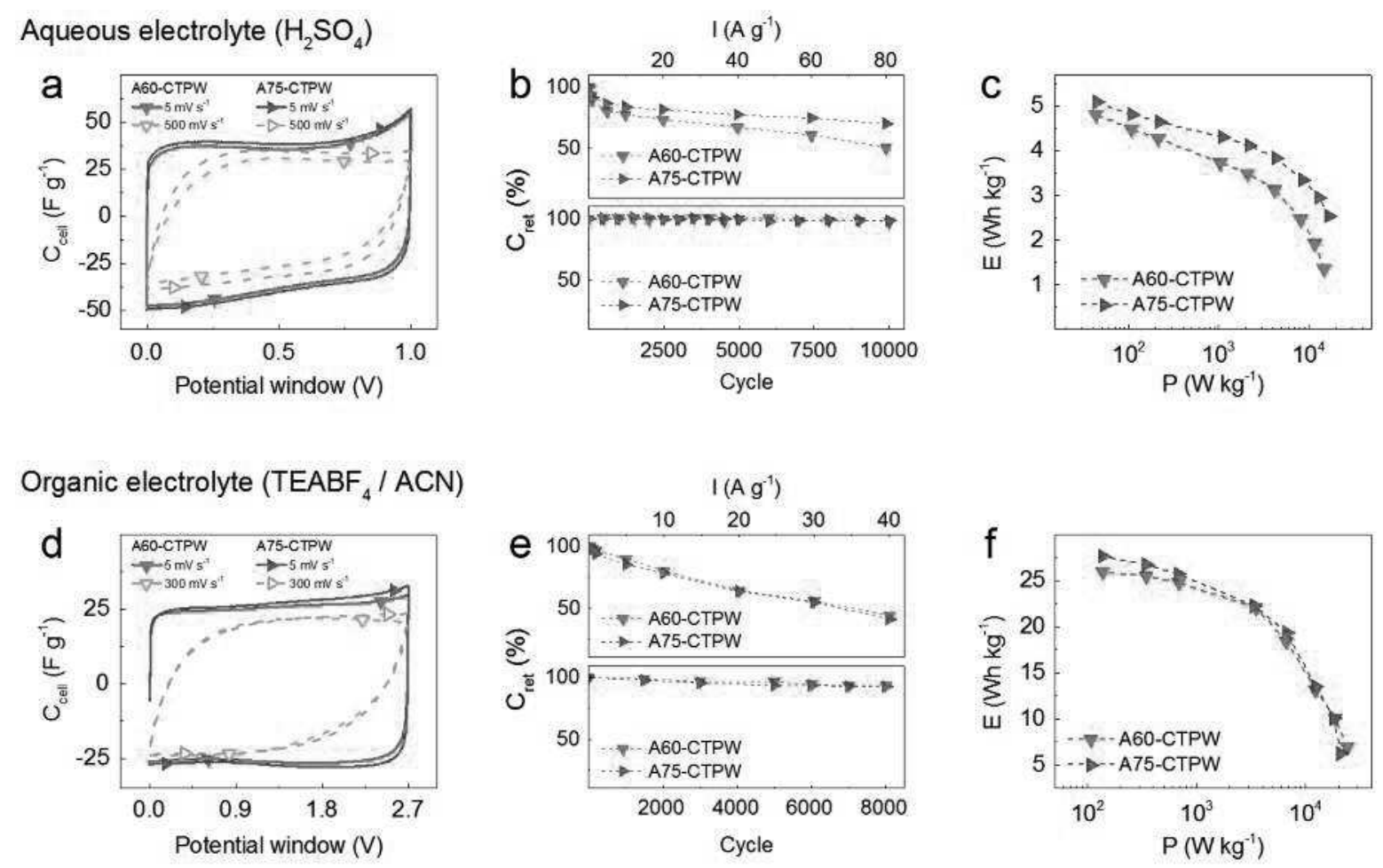

Figure 4. Electrochemical performances in aqueous electrolyte $\left(1 \mathrm{M} \mathrm{H}_{2} \mathrm{SO}_{4}\right)$ of A60-CTPW and A75-CTPW: (a) CV curves at 5 and $500 \mathrm{mV} \mathrm{s}^{-1}$; (b) capacitance retention, $C_{\text {ret }}$, as a function of applied current (top) and after continuous cycling at $5 \mathrm{~A} \mathrm{~g}^{-1}$ (bottom); (c) Ragone-like plot obtained from GCD tests. Electrochemical performances in organic electrolyte (1 M $\mathrm{TEABF}_{4} / \mathrm{ACN}$ ) of A60-CTPW and A75-CTPW: (d) CV curves at 5 and $300 \mathrm{mV} \mathrm{s}^{-1}$; (e) $C_{\text {ret }}$ with applied current (top), and after continuous cycling at $5 \mathrm{~A} \mathrm{~g}^{-1}$ (bottom); (f) Ragone-like plot obtained from GCD tests.

The capacitance values achieved by the materials synthesised herein are comparable with other un-doped mesoporous carbons of similar properties reported in the literature, see Table $\mathrm{S} 3,{ }^{13,34-44}$ but the AOMCs of this study present higher rate capability compared to the values usually reported for this type of materials (see Figure 5). In aqueous electrolyte (Figure 5a), the values of 
$C_{\text {ret }}$ of A60- and A75-CTPW are higher than the values reported both for disordered mesoporous carbons synthesised either from activated bio-sourced materials ${ }^{36,38}$ or from precursors of petrochemical origin, ${ }^{39,40}$ and for hard-templated OMCs derived from tannin, phenols, furfuryl alcohol or lignin..$^{37,41,42}$ Even more, AOMCs produced through pH-controlled self-assembly of tannin and further $\mathrm{CO}_{2}$ activation led to lower retentions than those presented herein. ${ }^{14}$ On the other hand, in organic electrolyte (Figure $5 b$ ), $C_{r e t}$ is in general comparable to the values from the literature. However, the synthesis of the formerly reported materials involved the use of dangerous or toxic substances for etching out hard templates ${ }^{40,41,44}$ or for activating the carbon material with $\mathrm{NaOH}^{45}$ or $\mathrm{ZnCl}_{2} \cdot{ }^{46}$ In contrast, the synthesis of the AOMCs presented herein does not require the use of hazardous chemicals. 

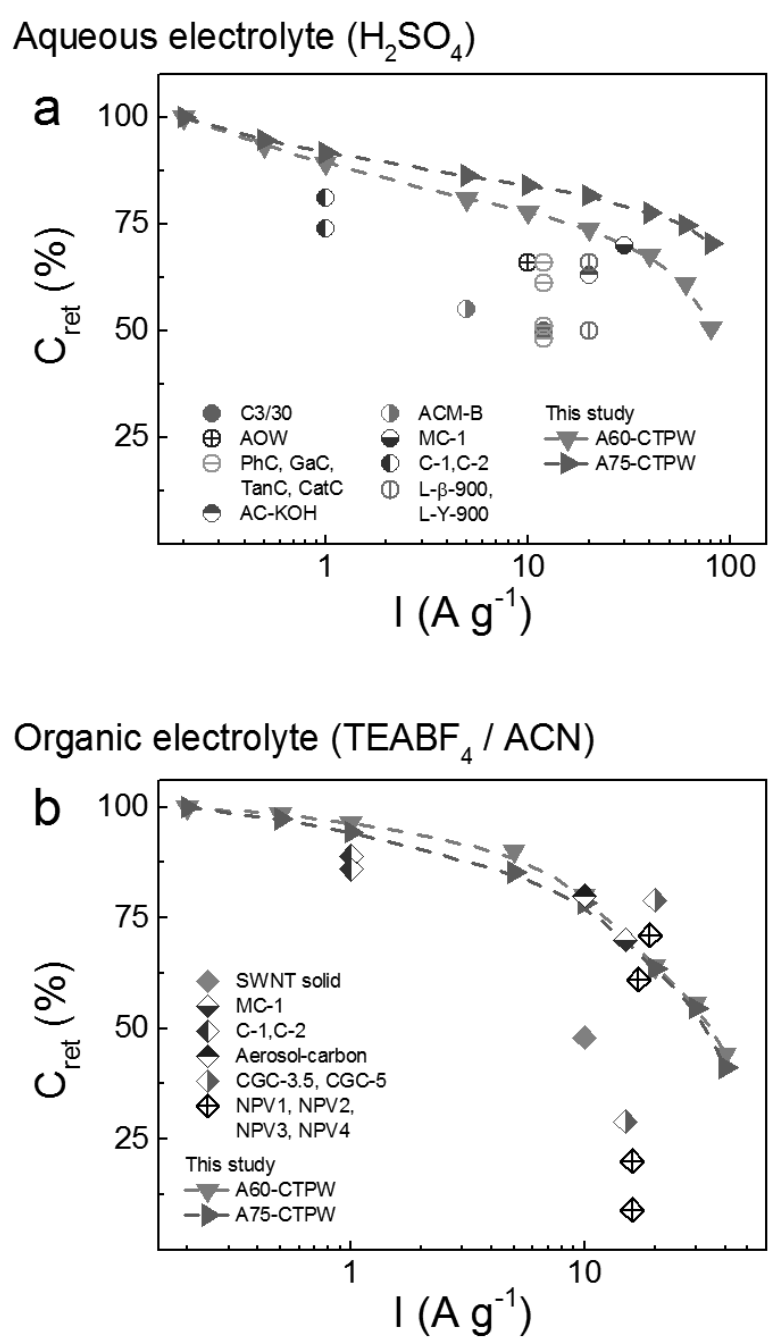

Figure 5. Capacitance retention for the AOMCs of this study in comparison with similar materials reported in the literature. ${ }^{14,36-46}$ The sample names correspond to those of their respective bibliographic references.

Additionally, some of these former studies used electrodes with lower carbon loads (CLs) 36,42,44-46 than those of the present study. Now, it is well known that a very low CL may lead to an overestimation of the capacitance of a material and certainly does improve the rate capability. For this reason, CLs close to that of commercial devices, i.e., $\sim 10 \mathrm{mg} \mathrm{cm}^{-2}$, are used here as such 
value is usually recommended for realistic studies. ${ }^{19,47}$ Additional GCD tests were then performed with a CL of $5.7 \pm 0.5 \mathrm{mg} \mathrm{cm}^{-2}$ for the sake of comparison; Figure $\mathrm{S} 7$ shows $C_{\text {cell }}$ and $C_{r e t}$ of supercapacitor cells with CLs of $\sim 10$ and $\sim 6 \mathrm{mg} \mathrm{cm}^{-2}$. As expected, higher values of $C_{c e l l}$ with increasing rate are found when using lower CLs. This finding demonstrates the difficulty of doing relevant comparisons with literature data. It also points out the outstanding values of $C_{\text {ret }}$ of the materials presented herein and tested under realistic conditions.

Although $\mathrm{H}_{2} \mathrm{SO}_{4}$ and $\mathrm{TEABF}_{4} / \mathrm{ACN}$ are widely used at laboratory and commercial scales, respectively, they still have the disadvantage of being hazardous substances. Thus, attention has been drawn to neutral aqueous electrolytes, as they are safer and can reach larger potential windows than the acidic ones. ${ }^{48}$ Considering this, the electrochemical performances of A60CTPW and A75-CTPW in $\mathrm{Na}_{2} \mathrm{SO}_{4}$ were tested and the main results are reported in Figure S8a. The materials again exhibits a supercapacitor behaviour as reflected in the rectangular curves obtained from $\mathrm{CV}$ tests at $5 \mathrm{mV} \mathrm{s}^{-1}$ within a potential window of $1.6 \mathrm{~V}$ (Figure S8b). From the GCD, it is observed that the values of $C_{\text {cell }}$ are $\sim 30 \%$ lower than those reached in $\mathrm{H}_{2} \mathrm{SO}_{4}$ probably due to the lower pseudocapacitance contribution in neutral electrolytes and in the range of values previously reported for similar materials. ${ }^{49-51}$ Figure S8b also shows that the values of $C_{\text {ret }}$ at $20 \mathrm{~A} \mathrm{~g}^{-1}$ are 69 and $67 \%$ for A60-CTPW and A75-CTPW, respectively, compared to the corresponding $C_{\text {ret }}$ of 74 and $82 \%$ at the same applied current in acidic medium (Figure $4 \mathrm{~b}$ ). This decrease in rate capability, commonly observed in neutral electrolytes, may be due to the larger size and lower mobility of the $\mathrm{Na}^{+}$ions relative to the $\mathrm{H}^{+}$ions, ${ }^{52}$ resulting in hindered diffusion at high rates. As expected, the values of specific energy achieved by the AOMCs in $\mathrm{Na}_{2} \mathrm{SO}_{4}$ are higher than those reached in acidic medium, because of the larger potential window, as shown in Figure S8c. The lower values of $C_{c e l l}$ in $\mathrm{Na}_{2} \mathrm{SO}_{4}$ are counterbalanced by the broader 
potential window, resulting in a difference of $\sim 3-4 \mathrm{Wh} \mathrm{kg}^{-1}$ between the maximum values of achieved stored energy with respect to $C_{\text {cell }}$ in $\mathrm{H}_{2} \mathrm{SO}_{4}$, which represents an increase of more than $60 \%$. Besides, the assembled SCs exhibit high long-term stability after continuous cycling at $5 \mathrm{~A}$ $\mathrm{g}^{-1}$, with $C_{\text {ret }}$ remaining at $96 \%$ after 10000 cycles, see Figure S8d.

Finally, for comparison, Figure S9 shows the values of gravimetric and volumetric singleelectrode capacitance $\left(C_{e}\right)$, as well as the energy and power densities for the AOMCs in the three electrolytes used in this study $\left(\mathrm{H}_{2} \mathrm{SO}_{4}, \mathrm{Na}_{2} \mathrm{SO}_{4}\right.$ and $\left.\mathrm{TEABF}_{4} / \mathrm{ACN}\right)$. The volumetric values were obtained by using the packing density of the electrodes, $0.50 \mathrm{~g} \mathrm{~cm}^{-3}$ (determined by measuring the thickness of the electrodes with a non-contact profilometer), and taking into account the amount of active material they contain, $85 \% .{ }^{53}$ Although the performance evaluated by the volumetric parameters is lower than that obtained with the gravimetric ones, the electrodes used in this study were not pressed, so the volumetric performance might be further improved by calendering. Note that the maximum achievable packing density is $0.74 \mathrm{~g} \mathrm{~cm}^{-3}$ for A60-CTPW and $0.62 \mathrm{~g} \mathrm{~cm}^{-3}$ for A75-CTPW, which are their respective particle densities.

\section{Conclusion}

High surface area-carbon materials were obtained by physical activation of tannin-derived OMCs. $\mathrm{CO}_{2}$ activation preserves the $2 \mathrm{D}$ hexagonal ordered mesoporous structure and increases both the connectivity between micro- and mesopores and the oxygen content at the material surface. Activation for 60 or 75 min produces materials with an adequate balance between high surface area and suitable pore size distribution that results in a high performance in both aqueous and organic electrolytes. The tested materials display square-shaped CV curves and exhibit high values of capacitance and high specific energy and power. The higher connectivity is especially 
important at high charge/discharge rates, resulting in high rate capability with capacitance retentions up to $70 \%$ at $80 \mathrm{~A} \mathrm{~g}^{-1}$. In addition, the AOMCs present very good long-term stability over time and after continuous cycling under realistic testing conditions. In conclusion, the easy synthesis, the use of an environment-friendly precursor and the good electrochemical performances of these tannin-derived AOMCs make them suitable candidates to be used as electrodes in supercapacitors.

\section{Associated content}

Supporting Information. The Supporting Information is available free of charge on the ACS Publications website.

Supporting Figures and Tables including: porous texture parameters, SAXS measurements, EA and XPS data, GCD curves, capacitance retention by potentiostatic hold, Nyquist plots, data from the literature compared to the results of this study, cell specific capacitance and capacitance retention from GCD tests for different carbon loads, and electrochemical performances compared in three different electrolytes. (PDF)

\section{Author information}

\section{Corresponding Author}

* E-mail: vanessa.fierro@univ-lorraine.fr

\section{Acknowledgements}

Jimena Castro-Gutiérrez gratefully acknowledges CONACYT-SENER (601021/438978) for the assigned scholarship to support her $\mathrm{PhD}$ studies, resulting in the work presented herein. This 
study was partly supported by the French PIA project "Lorraine Université d'Excellence", reference ANR-15-IDEX-04-LUE, and TALiSMAN project, funded by FEDER (2019-000214). Marta Sevilla thanks funding by Spanish MINECO-FEDER (CTQ2015-63552-R). Special thanks to Philippe Gadonneix for his help in the laboratory and with the elemental analysis measurements.

\section{References}

(1) Wang, Y.; Song, Y.; Xia, Y. Electrochemical Capacitors: Mechanism, Materials, Systems, Characterization and Applications. Chemical Society Reviews 2016, 45 (21), 5925-5950. https://doi.org/10.1039/C5CS00580A.

(2) González, A.; Goikolea, E.; Barrena, J. A.; Mysyk, R. Review on Supercapacitors: Technologies and Materials. Renewable and Sustainable Energy Reviews 2016, 58, 11891206. https://doi.org/10.1016/j.rser.2015.12.249.

(3) Sharma, P.; Bhatti, T. S. A Review on Electrochemical Double-Layer Capacitors. Energy Conversion and Management 2010, $51 \quad$ (12), 2901-2912. https://doi.org/10.1016/j.enconman.2010.06.031.

(4) Sevilla, M.; Mokaya, R. Energy Storage Applications of Activated Carbons: Supercapacitors and Hydrogen Storage. Energy Environ. Sci. 2014, 7 (4), 1250-1280. https://doi.org/10.1039/C3EE43525C.

(5) Yang, B.; Chen, J.; Liu, L.; Ma, P.; Liu, B.; Lang, J.; Tang, Y.; Yan, X. 3D Nitrogen-Doped Framework Carbon for High-Performance Potassium Ion Hybrid Capacitor. Energy Storage Materials 2019, S2405829719303319. https://doi.org/10.1016/j.ensm.2019.04.008.

(6) Lim, E.; Jo, C.; Lee, J. A Mini Review of Designed Mesoporous Materials for EnergyStorage Applications: From Electric Double-Layer Capacitors to Hybrid Supercapacitors. Nanoscale 2016, 8 (15), 7827-7833. https://doi.org/10.1039/C6NR00796A.

(7) Gao, Z.; Zhang, Y.; Song, N.; Li, X. Biomass-Derived Renewable Carbon Materials for Electrochemical Energy Storage. Materials Research Letters 2017, 5 (2), 69-88. https://doi.org/10.1080/21663831.2016.1250834.

(8) Sánchez-Sánchez, Á.; Centeno, T. A.; Suárez-García, F.; Martínez-Alonso, A.; Tascón, J. M. D. The Importance of Electrode Characterization to Assess the Supercapacitor Performance of Ordered Mesoporous Carbons. Microporous and Mesoporous Materials 2016, 235, 1-8. https://doi.org/10.1016/j.micromeso.2016.07.052.

(9) Liang, C.; Li, Z.; Dai, S. Mesoporous Carbon Materials: Synthesis and Modification. Angewandte Chemie International Edition 2008, $47 \quad$ (20), 3696-3717. https://doi.org/10.1002/anie.200702046. 
(10) Yao, H.; Zheng, G.; Li, W.; McDowell, M. T.; Seh, Z.; Liu, N.; Lu, Z.; Cui, Y. Crab Shells as Sustainable Templates from Nature for Nanostructured Battery Electrodes. Nano Letters 2013, 13 (7), 3385-3390. https://doi.org/10.1021/n1401729r.

(11) Liu, D.; Yuan, P.; Tan, D.; Liu, H.; Wang, T.; Fan, M.; Zhu, J.; He, H. Facile Preparation of Hierarchically Porous Carbon Using Diatomite as Both Template and Catalyst and Methylene Blue Adsorption of Carbon Products. Journal of Colloid and Interface Science 2012, 388 (1), 176-184. https://doi.org/10.1016/j.jcis.2012.08.023.

(12) Xu, F.; Chen, Y.; Tang, M.; Wang, H.; Deng, J.; Wang, Y. Acid Induced Self-Assembly Strategy to Synthesize Ordered Mesoporous Carbons from Biomass. ACS Sustainable Chemistry \& Engineering 2016, $4 \quad$ (8), 4473-4479. https://doi.org/10.1021/acssuschemeng.6b01196.

(13) Schlienger, S.; Graff, A.-L.; Celzard, A.; Parmentier, J. Direct Synthesis of Ordered Mesoporous Polymer and Carbon Materials by a Biosourced Precursor. Green Chem. 2012, 14 (2), 313-316. https://doi.org/10.1039/C2GC16160E.

(14) Sanchez-Sanchez, A.; Izquierdo, M. T.; Medjahdi, G.; Ghanbaja, J.; Celzard, A.; Fierro, V. Ordered Mesoporous Carbons Obtained by Soft-Templating of Tannin in Mild Conditions. Microporous and Mesoporous Materials 2018, 270, 127-139. https://doi.org/10.1016/j.micromeso.2018.05.017.

(15) Braghiroli, F. L.; Fierro, V.; Parmentier, J.; Pasc, A.; Celzard, A. Easy and Eco-Friendly Synthesis of Ordered Mesoporous Carbons by Self-Assembly of Tannin with a Block Copolymer. Green Chem. 2016, 18 (11), 3265-3271. https://doi.org/10.1039/C5GC02788H.

(16) Zhang, P.; Wang, L.; Yang, S.; Schott, J. A.; Liu, X.; Mahurin, S. M.; Huang, C.; Zhang, Y.; Fulvio, P. F.; Chisholm, M. F.; et al. Solid-State Synthesis of Ordered Mesoporous Carbon Catalysts via a Mechanochemical Assembly through Coordination Cross-Linking. Nature Communications 2017, 8, 15020. https://doi.org/10.1038/ncomms15020.

(17) Castro-Gutiérrez, J.; Sanchez-Sanchez, A.; Ghanbaja, J.; Díez, N.; Sevilla, M.; Celzard, A.; Fierro, V. Synthesis of Perfectly Ordered Mesoporous Carbons by Water-Assisted Mechanochemical Self-Assembly of Tannin. Green Chemistry 2018. https://doi.org/10.1039/C8GC02295J.

(18) Pizzi, A. Condensed Tannins for Adhesives. Industrial \& Engineering Chemistry Product Research and Development 1982, 21 (3), 359-369. https://doi.org/10.1021/i300007a005.

(19) Stoller, M. D.; Ruoff, R. S. Best Practice Methods for Determining an Electrode Material's Performance for Ultracapacitors. Energy \& Environmental Science 2010, 3 (9), 1294. https://doi.org/10.1039/c0ee00074d.

(20) Sevilla, M.; Ferrero, G. A.; Diez, N.; Fuertes, A. B. One-Step Synthesis of Ultra-High Surface Area Nanoporous Carbons and Their Application for Electrochemical Energy Storage. Carbon 2018, 131, 193-200. https://doi.org/10.1016/j.carbon.2018.02.021. 
(21) Weingarth, D.; Foelske-Schmitz, A.; Kötz, R. Cycle versus Voltage Hold - Which Is the Better Stability Test for Electrochemical Double Layer Capacitors? Journal of Power Sources 2013, 225, 84-88. https://doi.org/10.1016/j.jpowsour.2012.10.019.

(22) Thommes, M.; Kaneko, K.; Neimark, A. V.; Olivier, J. P.; Rodriguez-Reinoso, F.; Rouquerol, J.; Sing, K. S. W. Physisorption of Gases, with Special Reference to the Evaluation of Surface Area and Pore Size Distribution (IUPAC Technical Report). Pure and Applied Chemistry 2015, 87 (9-10). https://doi.org/10.1515/pac-2014-1117.

(23) Brunauer, S.; Emmett, P. H.; Teller, E. Adsorption of Gases in Multimolecular Layers. Journal of the American chemical society 1938, 60 (2), 309-319.

(24) Shi, H. Activated Carbons and Double Layer Capacitance. Electrochimica Acta 1996, 41 (10), 1633-1639.

(25) Lota, G.; Centeno, T. A.; Frackowiak, E.; Stoeckli, F. Improvement of the Structural and Chemical Properties of a Commercial Activated Carbon for Its Application in Electrochemical Capacitors. Electrochimica Acta 2008, 53 (5), 2210-2216. https://doi.org/10.1016/j.electacta.2007.09.028.

(26) Centeno, T. A.; Stoeckli, F. The Assessment of Surface Areas in Porous Carbons by Two Model-Independent Techniques, the DR Equation and DFT. Carbon 2010, 48 (9), 24782486. https://doi.org/10.1016/j.carbon.2010.03.020.

(27) Jagiello, J.; Ania, C.; Parra, J. B.; Cook, C. Dual Gas Analysis of Microporous Carbons Using 2D-NLDFT Heterogeneous Surface Model and Combined Adsorption Data of N2 and CO2. Carbon 2015, 91, 330-337. https://doi.org/10.1016/j.carbon.2015.05.004.

(28) Zuliani, J. E.; Caguiat, J. N.; Kirk, D. W.; Jia, C. Q. Considerations for Consistent Characterization of Electrochemical Double-Layer Capacitor Performance. Journal of Power Sources 2015, 290, 136-143. https://doi.org/10.1016/j.jpowsour.2015.04.019.

(29) Sanchez-Sanchez, A.; Martinez de Yuso, A.; Braghiroli, F. L.; Izquierdo, M. T.; Alvarez, E. D.; Pérez-Cappe, E.; Mosqueda, Y.; Fierro, V.; Celzard, A. Sugarcane Molasses as a Pseudocapacitive Material for Supercapacitors. RSC Advances 2016, 6 (91), 88826-88836. https://doi.org/10.1039/C6RA16314A.

(30) Braghiroli, F. L.; Fierro, V.; Szczurek, A.; Stein, N.; Parmentier, J.; Celzard, A. Electrochemical Performances of Hydrothermal Tannin-Based Carbons Doped with Nitrogen. Industrial Crops and Products 2015, 70, 332-340. https://doi.org/10.1016/j.indcrop.2015.03.046.

(31) Qu, D. Studies of the Activated Carbons Used in Double-Layer Supercapacitors. Journal of Power Sources 2002, 109 (2), 403-411. https://doi.org/10.1016/S0378-7753(02)00108-8.

(32) Chmiola, J.; Yushin, G.; Gogotsi, Y.; Portet, C.; Simon, P.; Taberna, P. L. Anomalous Increase in Carbon Capacitance at Pore Sizes Less Than 1 Nanometer. Science 2006, 313 (5794), 1760-1763. https://doi.org/10.1126/science.1132195.

(33) Huang, J.; Sumpter, B. G.; Meunier, V. A Universal Model for Nanoporous Carbon Supercapacitors Applicable to Diverse Pore Regimes, Carbon Materials, and Electrolytes. 
Chemistry - A European Journal 2008, $14 \quad$ (22), 6614-6626. https://doi.org/10.1002/chem.200800639.

(34) Chmiola, J.; Yushin, G.; Dash, R.; Gogotsi, Y. Effect of Pore Size and Surface Area of Carbide Derived Carbons on Specific Capacitance. Journal of Power Sources 2006, 158 (1), 765-772. https://doi.org/10.1016/j.jpowsour.2005.09.008.

(35) Hsieh, C.-T.; Teng, H. Influence of Oxygen Treatment on Electric Double-Layer Capacitance of Activated Carbon Fabrics. Carbon 2002, 40 (5), 667-674. https://doi.org/10.1016/S0008-6223(01)00182-8.

(36) Elmouwahidi, A.; Castelo-Quibén, J.; Vivo-Vilches, J. F.; Pérez-Cadenas, A. F.; Maldonado-Hódar, F. J.; Carrasco-Marín, F. Activated Carbons from Agricultural Waste Solvothermally Doped with Sulphur as Electrodes for Supercapacitors. Chemical Engineering Journal 2018, 334, 1835-1841. https://doi.org/10.1016/j.cej.2017.11.141.

(37) Sanchez-Sanchez, A.; Izquierdo, M. T.; Ghanbaja, J.; Medjahdi, G.; Mathieu, S.; Celzard, A.; Fierro, V. Excellent Electrochemical Performances of Nanocast Ordered Mesoporous Carbons Based on Tannin-Related Polyphenols as Supercapacitor Electrodes. Journal of Power Sources 2017, 344, 15-24. https://doi.org/10.1016/j.jpowsour.2017.01.099.

(38) Li, Z.; Zhang, L.; Amirkhiz, B. S.; Tan, X.; Xu, Z.; Wang, H.; Olsen, B. C.; Holt, C. M. B.; Mitlin, D. Carbonized Chicken Eggshell Membranes with 3D Architectures as HighPerformance Electrode Materials for Supercapacitors. Advanced Energy Materials 2012, 2 (4), 431-437. https://doi.org/10.1002/aenm.201100548.

(39) Ruiz, V.; Blanco, C.; Santamaría, R.; Ramos-Fernández, J. M.; Martínez-Escandell, M.; Sepúlveda-Escribano, A.; Rodríguez-Reinoso, F. An Activated Carbon Monolith as an Electrode Material for Supercapacitors. Carbon 2009, 47 (1), 195-200. https://doi.org/10.1016/j.carbon.2008.09.048.

(40) Li, Q.; Jiang, R.; Dou, Y.; Wu, Z.; Huang, T.; Feng, D.; Yang, J.; Yu, A.; Zhao, D. Synthesis of Mesoporous Carbon Spheres with a Hierarchical Pore Structure for the Electrochemical Double-Layer Capacitor. Carbon 2011, 49 (4), 1248-1257. https://doi.org/10.1016/j.carbon.2010.11.043.

(41) Fuertes, A. B.; Lota, G.; Centeno, T. A.; Frackowiak, E. Templated Mesoporous Carbons for Supercapacitor Application. Electrochimica Acta 2005, 50 (14), 2799-2805. https://doi.org/10.1016/j.electacta.2004.11.027.

(42) Ruiz-Rosas, R.; Valero-Romero, M. J.; Salinas-Torres, D.; Rodríguez-Mirasol, J.; Cordero, T.; Morallón, E.; Cazorla-Amorós, D. Electrochemical Performance of Hierarchical Porous Carbon Materials Obtained from the Infiltration of Lignin into Zeolite Templates. ChemSusChem 2014, 7 (5), 1458-1467. https://doi.org/10.1002/cssc.201301408.

(43) Futaba, D. N.; Hata, K.; Yamada, T.; Hiraoka, T.; Hayamizu, Y.; Kakudate, Y.; Tanaike, O.; Hatori, H.; Yumura, M.; Iijima, S. Shape-Engineerable and Highly Densely Packed Single-Walled Carbon Nanotubes and Their Application as Super-Capacitor Electrodes. Nature Materials 2006, 5 (12), 987-994. https://doi.org/10.1038/nmat1782. 
(44) Chen, Z.; Wen, J.; Yan, C.; Rice, L.; Sohn, H.; Shen, M.; Cai, M.; Dunn, B.; Lu, Y. HighPerformance Supercapacitors Based on Hierarchically Porous Graphite Particles. Advanced Energy Materials 2011, 1 (4), 551-556. https://doi.org/10.1002/aenm.201100114.

(45) Xu, B.; Wu, F.; Mu, D.; Dai, L.; Cao, G.; Zhang, H.; Chen, S.; Yang, Y. Activated Carbon Prepared from PVDC by $\mathrm{NaOH}$ Activation as Electrode Materials for High Performance EDLCs with Non-Aqueous Electrolyte. International Journal of Hydrogen Energy 2010, 35 (2), 632-637. https://doi.org/10.1016/j.ijhydene.2009.10.110.

(46) Rufford, T. E.; Hulicova-Jurcakova, D.; Fiset, E.; Zhu, Z.; Lu, G. Q. Double-Layer Capacitance of Waste Coffee Ground Activated Carbons in an Organic Electrolyte. $\begin{array}{llllll}\text { Electrochemistry } & \text { Communications } & \mathbf{2 0 0 9}, & 11 & \text { (5), } & \text { 974-977. }\end{array}$ https://doi.org/10.1016/j.elecom.2009.02.038.

(47) Gogotsi, Y.; Simon, P. True Performance Metrics in Electrochemical Energy Storage. Science 2011, 334 (6058), 917-918. https://doi.org/10.1126/science.1213003.

(48) Zhong, C.; Deng, Y.; Hu, W.; Qiao, J.; Zhang, L.; Zhang, J. A Review of Electrolyte Materials and Compositions for Electrochemical Supercapacitors. Chemical Society Reviews 2015, 44 (21), 7484-7539. https://doi.org/10.1039/C5CS00303B.

(49) Bichat, M. P.; Raymundo-Piñero, E.; Béguin, F. High Voltage Supercapacitor Built with Seaweed Carbons in Neutral Aqueous Electrolyte. Carbon 2010, 48 (15), 4351-4361. https://doi.org/10.1016/j.carbon.2010.07.049.

(50) Demarconnay, L.; Raymundo-Piñero, E.; Béguin, F. A Symmetric Carbon/Carbon Supercapacitor Operating at $1.6 \mathrm{~V}$ by Using a Neutral Aqueous Solution. Electrochemistry Communications 2010, 12 (10), 1275-1278. https://doi.org/10.1016/j.elecom.2010.06.036.

(51) Jiménez-Cordero, D.; Heras, F.; Gilarranz, M. A.; Raymundo-Piñero, E. Grape Seed Carbons for Studying the Influence of Texture on Supercapacitor Behaviour in Aqueous Electrolytes. Carbon 2014, 71, 127-138. https://doi.org/10.1016/j.carbon.2014.01.021.

(52) Lu, S.; Song, Y.; Guo, K.; Chen, X.; Xu, J.; Zhao, L. Effect of Aqueous Electrolytes on the Electrochemical Behaviors of Ordered Mesoporous Carbon Composites after $\mathrm{KOH}$ Activation as Supercapacitors Electrodes. Journal of Electroanalytical Chemistry 2018, 818, 58-67. https://doi.org/10.1016/j.jelechem.2018.04.025.

(53) Fuertes, A. B.; Ferrero, G. A.; Sevilla, M. Commentary: Methods of Calculating the Volumetric Performance of a Supercapacitor. Energy Storage Materials 2016, 4, 154-155. https://doi.org/10.1016/j.ensm.2016.05.002. 